\title{
Digitization of Law: Some Problematic Aspects
}

\author{
Valeev Damir Khamitovich ${ }^{1} \&$ Nuriev Anas Gaptraufovich ${ }^{1}$ \\ ${ }^{1}$ Kazan Federal Universitye, Russia \\ Correspondence: Valeev Damir Khamitovich, Kazan Federal Universitye, Russia. E-mail: valeev55@gmail.com
}

Received: June 9, 2019

Accepted: August 25, $2019 \quad$ Online Published: August 31, 2019

doi:10.5539/jpl.v12n5p135

URL: https://doi.org/10.5539/jpl.v12n5p135

\begin{abstract}
This article reveals the important practical importance of academic cooperation between legal doctrine and achievements of technical laboratories in terms of defining "points of growth" in questions of digitalization of law and development of legal tools aimed at regulating the technogenic factor on the one hand and legal support of "game-changing" results in a in the conditions of digital economy on the other hand. The important role of the transformation of social regulators, designed to regulate the "infrastructural" and "institutional" incorporation of "digital" technologies into the existing legal system, is noted. The current place of the Russian Federation on readiness for the digital economy is subject to, among other things, insufficient theoretical study as a result of the regulatory framework, which often does not act as a platform for growth, but rather contains many gaps - which have to be overcome at the expense of law enforcement practice. The article notes that the trend of "digitalization" of Russian law is closely linked to the need to maintain the ecosystem of the digital economy and to identify "growth points" and enforce their urgent character based on the state's resource base, defines a positive agenda for "digitalization" of Russian law and raises a number of questions for the Russian science. It is concluded that one of the topical issues in the framework of the "digitalization" of Russian law is legal robotics, which is perceived as the automation of workflows, the existence of interrelated algorithms of actions aimed at generating a predictable result based on some initial simulated and prescribed situation and maximum robotization of legal processes. Using the example of the Kazan Federal University, which proclaimed the promotion of innovative development of the focus areas of the Russian Federation as one of its missions, the achievements obtained as a result of the interaction of legal doctrine and technical laboratories are revealed.
\end{abstract}

Keywords: digital economy, digitalization of law, digital justice, transformation of procedural law, legal robotics, realization of a constitutional right for the judicial defense

\section{Introduction}

A "Breakthrough" in any area of life activity leads to the widely-used incorporations of "achievements" in all spheres of social relations. The trend of the last decade which is called "digitalization", has marked the rapid development of "information" technologies and has led to the transformation of social regulators designed to streamline the "infrastructural" and "institutional" incorporation of "digital" technologies into the existing legal system.

\section{Method}

In the study the following methods of scientific knowledge were used: inter-branch comparative method, dialectical, sociological, historical method. The key method was the interdisciplinary method by which the possibilities of interaction between humanitarian and technical sciences in the issues of "digitalization" of law were determined. The methodological basis of the study was made up of the general provisions of the science of the theory of state and law, civil procedural law

\section{Results}

As a result of the study, tendencies of "digitalization" of Russian law in the digital economy were determined. Using the example of the Kazan Federal University which proclaimed the promotion of innovative development of the focus areas of the Russian Federation as one of its missions, the achievements obtained as a result of the interaction of legal doctrine and technical laboratories are revealed.

\section{Discussion}

Digitization is not a unique phenomenon in relation to any national legal system, but it is a worldwide tendency 
due to the fact that data in digital form has become the basis for carrying out actions of legal matter. So, when adopting a program aimed at the development of the digital economy of the Russian Federation, a separate section of a program plan is devoted to the comparative analysis in the global digital market. From the point of view of the economic and innovative results of the use of digital technologies, the Russian Federation is in 38th place with a large lag behind the leading countries such as Finland, Switzerland, Sweden, Israel, Singapore, the Netherlands, the United States of America, Norway, Luxembourg and Germany. The Russian Federation is ranked 41 st in readiness for the digital economy with a significant difference from dozens of leading countries, such as Singapore, Finland, Sweden, Norway, the United States of America, the Netherlands, Switzerland, the United Kingdom, Luxembourg and Japan (Decree of the Government of the Russian Federation, 2017).

To a great extent, today's place of the Russian Federation on readiness for the digital economy is caused, among other things, by the regulatory and legal framework, which often serves not as a platform for growth, but on the contrary, contains a lot of gaps - that have to be overcome by the law enforcement practice (Safin, 2016; Nuriev and Khodzhiev, 2015; Valeev and Golubtzov, 2014) .

If initially "digitalization" was understood as a narrow sphere, which implies a transition from the analogue form of information transfer to digital, further the category "digitalization" was supplemented with new content and in a general sense, today it is the process of introducing "information" technologies into all spheres of public relations in order to ensure a better quality of life.

The trend of "digitalization" of Russian law is closely linked to the need to maintain the ecosystem of the digital economy, which is based on a partnership of organizations that ensure the continuous interaction of their own technological platforms, applied Internet services, analytical systems, information systems of state authorities of the Russian Federation, organizations and individuals (Decree of the President of the Russian Federation, 2017).

Currently, the guarantor of the Constitution of the Russian Federation - the President of the Russian Federation has set a task to create a system of legal regulation of the digital economy based on a flexible approach in each area, as well as introducing civil circulation based on digital technologies (Decree of the President of the Russian Federation, 2018). It is the effectiveness of normative regulators that will determine the process of creating an ecosystem of the digital economy of the Russian Federation, in which data in digital form is a key factor of production in all spheres of social and economic activity and in which effective interaction is ensured, including cross-border community, business, the scientific and educational communities, state and individuals.

Accordingly, the issue of "digitalization" of Russian law is put in the category of state tasks that should be successfully implemented in the foreseeable future. Determining growth points and giving them an urgent character based on the state resource base, of course, determines a positive agenda for the "digitalization" of Russian law and raises a number of questions for the modern Russian science.

One of the vital issues is an issue of automating workflows, the existence of interrelated algorithms of actions aimed at generating a predictable result based on some initially simulated and defined situation and the maximum robotization of legal processes. In general terms, these processes can be described as legal robotics.

It can be said that the term "Legal tech" has already been established in practice, which implies the introduction of modern information technologies in the field of legal services, within the framework of which there are: (1) general technology providing for the possibility of usage of other digital tools (systems of cloud keeping and computer security); (2) organizational support technologies that increase the efficiency of business movement within the organization; (3) technologies for solving basic legal problems:

- online services offering typical solutions for a specific category of legal issues that can be standardized;

- technologies that simplify the implementation of tasks that do not require decent skill, such as preparing and analyzing standard contracts, identifying problematic provisions in documents for further analysis;

- technologies that reduce the labor intensity of a lawyer's work, in particular, the analysis of data from previous court decisions and the assessment of the prospects for the proceedings in the current case (Wikipedia. 2018).

The process of automating work processes is largely inevitable, given the vast array of regulatory and law enforcing material. As noted by I.N. Senyakin and V.N. Barsukova, given the scale of the current regulatory framework, the process of systematization is very laborious. Even with a high level of professionalism of law enforcement agencies, it is very difficult to take into account all the existing regulatory requirements and to create an effective normative act, while excluding all provisions that contradict it and including the necessary ones from other documents. Therefore, in our age of technical progress and information technology, numerous automated information systems have been created. The most frequent use is experienced by automated information retrieval systems (AIRS), reference and information systems (ARIS), expert legal systems (ELS), as 
well as automated workplaces (AWP) (Senyakin and Barsukova. 2018, p. 62).

The Kazan Federal University, which declared as one of its missions the promotion of innovative development of the focus areas of the Russian Federation, cannot stand aside from the issues of generation, concentration and dissemination of knowledge, competencies and technologies in response to the global challenges of our time. For example, educational programs in the field of robotics are being actively developed, in particular, the Higher Institute of Information Technologies and Intelligent Systems of KFU has developed the first soft-robotics educational program in Russia under the master's program Intellectual Robotics. Students learn to create software for robots, and the robots are at their disposal at the time of their studies. Classes are taught in English.

Questions of robotics are studied by several structural subdivisions of the KFU, with which the Law Faculty cooperates in these issues and, for its part, conducts legal research on the problems of using artificial intelligence technology in the field of jurisprudence and expert support of the practical activities of partner institutions in creating an integrated automated supporting system for making decisions by the court using artificial intelligence technologies (Senyakin and Barsukova, 2018; Jones, 2005):

1) Institute of Computational Mathematics and Information Technology of KFU, one of the areas of which is the issues of artificial intelligence, as well as ways to develop application software. The development of this direction is vital due to the need to improve the organization of the work of computer complexes consisting of machines of various types, computer networks and information systems, automated controlling and planning systems.

2) Higher Institute of Information Technology and Intelligent Systems of KFU. The main areas of research are aimed at: text analysis and processing of unstructured data; intelligent robotics; intelligent self-learning systems. Within this structural division there are: Department of Intellectual Robotics; The Laboratory of Intelligent Robotic Systems (LIRS), which among other things is engaged in research of the Internet of things and cloud technologies.

3) Engineering Center of KFU. The main tasks of the center are support and maintenance of various enterprises in the region in the field of industrial automation and robotization.

Cooperating with the number of "growth centers" the following joint research is carried out by the Faculty of Law on issues of robotics:

1) Together with the Institute of Computational Mathematics and Information Technology of KFU an educational simulator "Judge Robot" is being developed. A unique system of virtual trial simulation for the educational process of the law faculty of KFU. The system allows to choose procedural roles in the conditions of remote access, to imitate a trial with automatic generation of a case plot, to checking the quality of preparation of procedural documents by students, including a judicial act. The expert decision-making system that underlies the educational simulator in the future can become the basis for the future integrated automated decision support system for procedural decisions by the court using artificial intelligence technologies.

2) Together with the Higher Institute of Information Technology and Intelligent Systems of KFU, the "Lawyer Robot" information system is being developed. "Lawyer Robot" is an information system that should allow participants in the legal process to properly prepare the case, as well as plan for judicial activities. The task of the system is to help to determine the nature of the dispute, to search for and verify the validity of legal norms governing disputed legal relations, to assist in finding a competent court (its jurisdiction), the status of participants in the dispute (active, liquidated, bankrupt), determining the range of circumstances relevant to consideration of the dispute, the nature of the disputed relationship, the law to be applied (if this provision is in effect), and also to check the sufficiency and completeness of the submitted documents.

3) also, the project "A single window of legal assistance" (an interdepartmental system for working with individuals' requests) is at the development stage. It is based on the developments of such countries as South Korea, Estonia and New Zealand. This will be a service for the systematic work with the legal issues of individuals. In the Single Window, it will be possible to get online advice, draw up and file a lawsuit, appeal against a fine, etc. Citizens can ask a question on the website of any authority and get an answer within a few hours. You do not need to register if you already have an account on the portal of state services of the Republic of Tatarstan.

"A single window of legal assistance" will be the first step towards the robotization of this sphere. With the help of unique technologies of a website pravoved.ru on the basis of neural networks it will be possible to fully automate the answers to $90 \%$ of individuals' requests. In the future, it will be possible to expand the legal services of the Single Window, reducing budget expenditures and the burden on civil servants. 
Thus, the first steps in joint research have been made, it remains only to analyze and identify prospects for further development.

\section{Summary}

Questions of robotics are studied by several structural subdivisions of the KFU, with which the Law Faculty cooperates in these issues and, for its part, conducts legal research on the problems of using artificial intelligence technology in the field of jurisprudence and expert support of the practical activities of partner institutions in creating an integrated automated supporting system for making decisions by the court using artificial intelligence technologies. The following subdivisions of KFU are dealing with the questions of robotics: 1) Institutions of Computational Mathematics and Information Technologies of KFU, one of the directions of which is the questions of artificial intelligence, as well as methods of developing application software; 2) Higher Institute of Information Technology and Intelligent Systems of KFU; 3) Engineering Center of KFU.

\section{Conclusion}

Having the "growth centers" in cooperation with the Law Faculty, the issues of "digitalization" and robotics are carried out a number of joint research engagements:

1) Together with the Institute of Computational Mathematics and Information Technologies of KFU an educational simulator "Judge Robot" is being created. It is a unique system of virtual trial simulation for the educational process of the Law Faculty of KFU.

2) Together with the Higher Institute of Information Technology and Intelligent Systems of KFU, the "Lawyer Robot" information system is being developed. "Lawyer Robot" is an information system that shall allow participants in the legal process to properly prepare the case, as well as plan for judicial activities.

3) The project "Single Window of Legal Assistance" (inter-department system for work with individuals' requests). This is a service for system work with legal issues of individuals. In the Single Window, it will be possible to get online advice, draw up and file a lawsuit, appeal against a fine, etc.

\section{Acknowledgements}

The reported study was funded by RFBR according to the research project № 18-29-16147 мк.

\section{References}

Decree of the Government of the Russian Federation. (2017). On establishment of the program "Digital economy of the Russian Federation. Legislation Bulletin of the Russian Federation dated 07.08.2017. № 32. Art. 5138.

Decree of the President of the Russian Federation. (2017). On the Strategy of development of the information society in the Russian Federation for 2017-2030. Legislation Bulletin of the Russian Federation dated 15.05.2017. № 20. Art. 2901.

Decree of the President of the Russian Federation. (2018). On national aims and strategic goals of development of the Russian Federation for the period until 2024. Legislation Bulletin of the Russian Federation dated 14.05.2018. № 20. Art. 2817.

Gold, N. (2004). Understanding Service Oriented Software. IEEE Software, 21(2), 71-77. https://doi.org/10.1109/MS.2004.1270766

Jones, S. (2005). Toward an Acceptable Definition of Service. IEEE Software, 22(3), 87-93. https://doi.org/10.1109/MS.2005.80

Nuriev, A. G., \& Khodzhiev, A. R. (2015). Procedural guarantees of rights of citizens of the Russian federation in the foreign states. Research Journal of Applied Sciences, 10(12), 832-834.

Safin, Z. F. (2016). Legal Issues Supporting Production and Distribution of Biotech Products. International journal of Advanced biotechnology and Research, 7(4), 1260-1264. https://doi.org/10.21474/IJAR01/866

Senyakin, I. N., \& Barsukova, V. N. (2018). Influence of information technologies on systematization of the modern civil procedural law. Herald of Civil Procedure, (1), 61-66. https://doi.org/10.24031/2226-0781-2018-8-1-60-79

Valeev, D. K., \& Golubtzov, V. G. (2014). Modernization of the Russian law: a review of the laws on enforcement proceedings. Life Science Journal, 11(8s), 234-238.

Wikipedia. (2018). The Free Encyclopedia. Retrieved October 23, 2018, from https://ru.wikipedia.org/wiki/Legal_tech\#cite_note-ltr5-6-4 


\section{Copyrights}

Copyright for this article is retained by the author(s), with first publication rights granted to the journal.

This is an open-access article distributed under the terms and conditions of the Creative Commons Attribution license (http://creativecommons.org/licenses/by/4.0/). 